\title{
Propuesta De Un Modelo Alternativo De Funcionamiento Del Sistema Turístico
}

\author{
Manuel Antonio Abarca Zaquinaula (Lic. Tur.Msc.) \\ Universidad / Escuela Superior Politécnica de Chimborazo \\ Extensión Norte Amazónica de la República del Ecuador
}

doi: 10.19044/esj.2017.v13n17p340 URL:http://dx.doi.org/10.19044/esj.2017.v13n17p340

\begin{abstract}
The present study shows an alternative proposal of operation of the tourist system from the perspective of mechanics and their coordinated, harmonious, and routine interrelation between its parts. This study was carried out based on the tourism systems proposed by Roberto Boullón, Neil Leiper, and the World Tourism Organization. The problems that affected the development of tourism in a society was analyzed. It established a systemicmechanical model of four parts rector of the tourist system, real and potential demand, geographical space, and offers tourist system which are interrelated to each other. All have the same importance, different objectives, and the same purpose to satisfy fully the needs for transportation, lodging, food and recreation of the actual and potential tourist demand. This is achieved through the coordinated and effective functioning of the servers and/or entrepreneurs of the geographic space and the vehicle that the tourist offers. Subsequently, it would help to improve and streamline their tourism services and products by adapting them to their needs and trends. This is with the aim of returning them to their place of residence. The present article emphasizes the importance of observing the tourist system as the basic unit in the development of the tourist industry. It states that the lack of understanding of its operation is what has not allowed this industry to develop fully around the world.
\end{abstract}

Keywords: tourism system, mechanics, tourist cluster, ecological niche.

\section{Resumen}

El presente ensayo expresa una propuesta alternativa de funcionamiento del sistema turístico, desde la perspectiva de la mecánica y su interrelación coordinada, armónica y rutinaria entre sus partes; con base en los sistemas turísticos propuestos por Roberto Boullón, Neil Leiper y la Organización Mundial de Turismo, se analizó la problemática de los 
factores que no permiten que se desarrolle el turismo en una sociedad, estableciendo un modelo sistémico-mecánico de cuatro partes (órgano rector del sistema turístico, demanda real y potencial, espacio geográfico y oferta del sistema turístico) interrelacionadas entre sí, todas con la misma importancia, con objetivos diferentes y una misma finalidad, la de satisfacer a plenitud las necesidades de:transporte, hospedaje, alimentación y recreación de la demanda turística real y potencial, a través del funcionar coordinado y efectivo de los servidores y/o empresarios del espacio geográfico y motor de la oferta turística, que al llegar la información de las exigencias y tendencias de la demanda, por el órgano rector del turismo, mejoran y dinamizan sus servicios y productos turísticos, adaptándolos a sus exigencias y tendencias, con la finalidad de volver a ofertarlos en su lugar de residencia. El presente artículo resalta la importancia de observar al sistema turístico como la unidad base en el desarrollo de la industria turística, y que la no comprensión de su funcionamiento, es lo que, no ha permitido que esta industria se desarrolle a plenitud alrededor del mundo.

Palabras clave: sistema turístico, mecánica, clúster turístico, nicho ecológico.

\section{Introducción}

Se denomina turismo a todas las actividades que realizan las personas durante los viajes y estancias en lugares distintos a su entorno habitual por un periodo de tiempo consecutivo inferior a un año y más de veinticuatro horas, con fines de: ocio, por negocios, salud, educación y otros. Los seres humanos desde sus orígenes se han visto impulsados a trasladarse a diferentes emplazamientos, por distintas razones, caza, religión, comercio, guerras, ocio etc ( Sancho, 1998).

Estas actividades actualmente se realizan por todo el globo terrestre, permitiendo viajar a millones de personas, generando millones de divisas, distribuidas en miles de destinos turísticos, a su vez, redistribuidas a miles de elementos directos e indirectos del turismo, pero aún no se comprende en su totalidad el funcionamiento ideal, efectivo y rentable del sistema turístico, que permita el desarrollo a plenitud de esta industria y contar con sus múltiples impactos positivos. Es evidente que en varios destinos con tantas potencialidades de atractivos turísticos naturales, culturales, artificiales y ventajas comparativas biogeográficas, no se desarrollan turísticamente como deberían hacerlo y son sujetos de impactos económicos, socio-culturales y ambientales negativos.

Para ello varios autores como: Roberto Boullón, Neil Leiper, la Organización Mundial de Turismo, entre otros, han asumido esta problemática en sus estudios. Sin embargo, aún existen vacíos en lo referente 
al funcionamiento ideal, rentable y efectivo del sistema turístico, ya que, su funcionamiento debe ser armónico, coordinado y rutinario, permitiendo el trabajo eficiente de los servidores y/o empresarios del motor de la oferta turística, quienes deben adaptarse a las exigencias y tendencias de la demanda, al recibir información fluida de su comportamiento, de parte del órgano rector del turismo, y a través de la innovación tecnológica turística se debe dar uso sostenible a los recursos naturales, culturales y artificiales generando productos turísticos competitivos, que le permitan al sector desarrollarse y mejorar la calidad de vida de sus habitantes.

El presente ensayo va analizar la problemática antes mencionada y proponer un modelo de funcionamiento sistémico-mecánico del sistema turístico y los factores determinantes para su desarrollo.

\section{Metodología}

Antes de desarrollar el enfoque metodológico, es necesario establecer el significado de los términos que se están usando (sistema turístico, mecánica, clúster turístico, nicho ecológico), de esta manera se pretende ser más efectivos (pertinentes) en el desarrollo de la metodología. Existen numerosas acepciones que pueden tomar los términos propuestos, las cuales dependen del área en que se aplique (medicina, ingeniería, gerencia, entre otros). Es conveniente partir de los conceptos generales y los aceptados en las experiencias desarrolladas sobre el tema de funcionamiento de sistemas.

Sistema turístico: existen varios conceptos de sistema turístico con sus respectivos subsistemas y/o partes dependiendo del autor que se cite, para el presente ensayo se tomará en cuenta el concepto dado por la Organización Mundial de Turismo, en el que expone que el sistema turístico es un resultado complejo de interrelaciones entre diferentes factores que hay que considerar conjuntamente desde una óptica sistemática, es decir, un conjunto de elementosinterrelacionados entre sí que evolucionan dinámicamente. Concretamente, se distinguen cuatro elementos básicos en el concepto de actividad turística: la demanda, la oferta, el espacio geográfico y los operadores del mercado (Sancho, 1998).

Mecánica: es una rama de la física que estudia el movimiento de los cuerpos y conjuntos de elementos que forman un motor o cualquier sistema que requiera armonía y sincronía en la ejecución de una tarea. La palabra Mecánica proviene del Latín Mechanìca y significa "Arte de fabricar maquinas” por lo que nos basamos en la idea de que más que un concepto estático que se centra en análisis de un comportamiento rotativo, la mecánica se refiere a todo aquello a lo que se le asigna un recorrido y este se repite tantas veces sea necesario. Actualmente, el uso de la mecánica se emplea para todo tipo de creación de nuevas tecnologías, la mecánica es renovada y construida en base a los fundamentos de una esencia clave que es la rutina. 
Un proceso de producción en serie requiere un mecanismo de regulación y soporte capaz de aguantar los embates de un agente externo que intente desestabilizar la mecánica del proyecto en ejecución (Orozco, 2014)

Clúster turístico: es una configuración especial que surge en el contexto de la globalización, tiene como propiedad principal el estrechamiento de las relaciones entre las organizaciones para crear una red de sinergias; su objetivo es el desarrollo de estrategias competitivas conjuntas, creando y entregando mayor valor al mercado, por medio de relaciones cooperativas entre empresas independientes que tienen un mismo objetivo, aunque compitan entre si. El clúster turístico busca su posición competitiva a escala global a través de un espacio tridimensional, que combina estrategias competitivas, estrategias cooperativas y estrategias de relaciones con el cliente que, con sus necesidades, deseos y expectativas, optimizan la configuración del sistema, retroalimentándolo con el proceso simultáneo de producción, consumo y evaluación (Masaro, 2008)

Nicho ecológico: es un término que describe la posición relacional de una especie o población en un ecosistema o en el espacio concreto que ocupa en el ecosistema. En otras palabras, cuando hablamos de nicho ecológico, nos referimos a todas las actividades que realiza (ocupación), o la función que desempeña cierto individuo dentro de una comunidad (Carabias \& Meave, 2009).

Para la elaboración de la presente propuesta alternativa de funcionamiento del sistema turístico, se empleó el enfoque sistémicomecánico, analizando los modelos de sistema turístico propuestos por Roberto Boullón, Neil Leiper y la Organización Mundial de Turismo, relacionando las similitudes y diferencias entre sus componentes, empleando los siguientes métodos teóricos; método analítico, método lógico y método de la concreción.

\section{Sistema turístico de Roberto Boullón}

En el grafico1, se presenta la propuesta de funcionamiento del sistema turístico de Roberto Boullón de su libro Planificación del Espacio Turístico, que se analizó en el presente ensayo. 
Gráfico1. Funionamiento del sistema turístico según Roberto Boullon

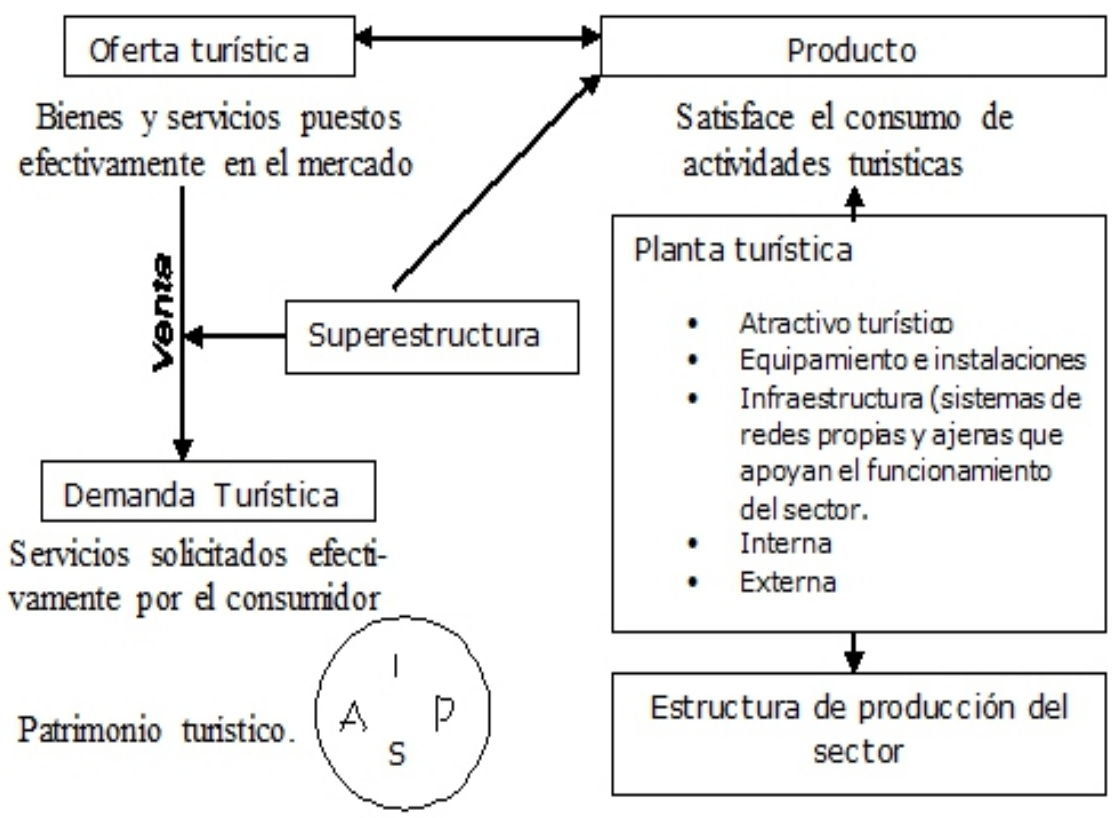

Fuente: Boullón (2006:32).

La partida del funcionamiento del sistema, se origina en el encuentro dela oferta con la demanda turística a través de un proceso de venta del llamado producto turístico, que junto a la infraestructura forman la estructura de producción del sector, tal como se indica en la parte derecha de la figura mencionada. En el centro de la misma se ha representado a la superestructura turística, cuya función es controlar la eficiencia del sistema, vigilando el funcionamiento e interrelación de las partes (Boullón, 2006).

Es evidente que no se observa en este modelo de funcionamiento del sistema turístico la unión y correlación existente entre cada una de sus partes, tipo ciclo de funcionamiento, más aún cuando no se establece claramente quien será el responsable de realizar las funciones de planeación, organización, dirección y control de todo el sistema, dejando al azar el encuentro entre la demanda y la oferta, sin identificar el espacio geográfico y el funcionamiento mecánico de todo el sistema turístico.

\section{Sistema turístico de Neil Leiper}

En el grafico 2, se presenta el modelo de sistema turístico propuesto por Neil Leiper, que se analizó en el presente esnsayo. 


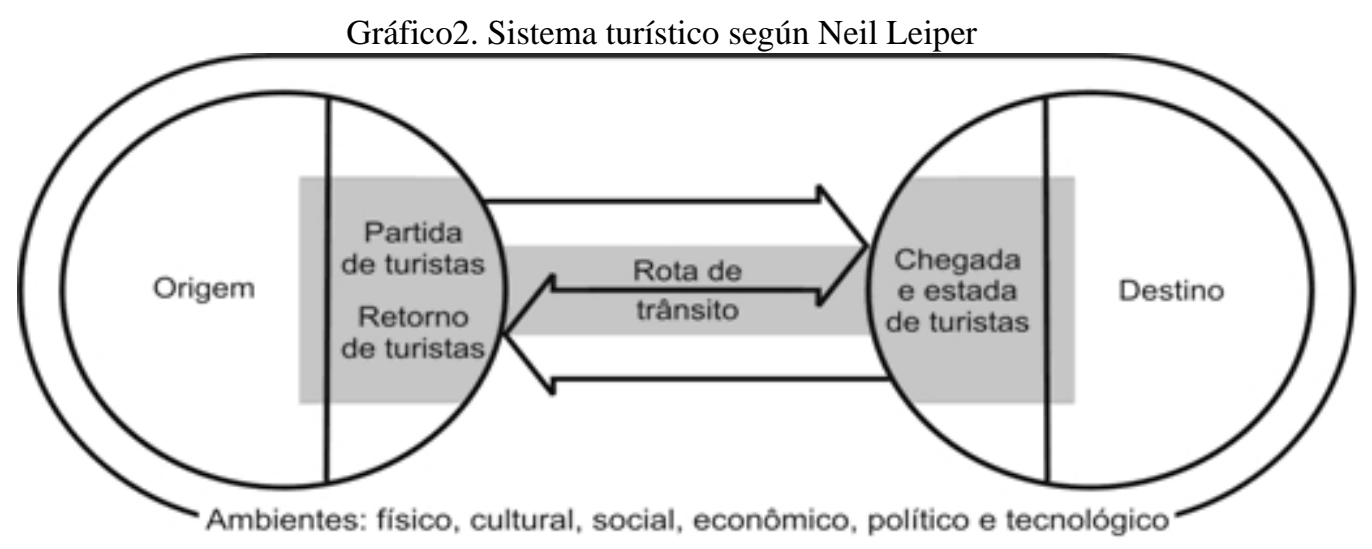

Indústria turistica

Fuente: Leiper (1979:404).

Con este diagrama Leiper agrega algunos conceptos. El resultado es un modelo fundamentalmente espacial pero con presencia de otras categorías de elementos. En este modelo denominado sistema de turismo, hay tres aspectos básicos:

Turistas: son los actores del sistema. Los turistas parten de su lugar de residencia, viajan al destino en el cual permanecen durante cierto tiempo y luego regresan al lugar de origen.

Elementos geográficos: el espacio emisor de visitantes que constituye la localidad de residencia habitual donde se generan recursos a ser gastados por el turismo, se busca información u se hacen reservas. El espacio receptor es la razón de existencia del turismo, motiva los desplazamientos y recibe los principales efectos de la actividad. El espacio de tránsito comprende todas las localidades por las cuales los turistas pasan hasta llegar al destino.

Industria turística: es el grupo de empresas y organizaciones involucradas en la oferta del producto turístico. Está representada en las tres regiones geográficas pero no en todo el espacio por lo cual siempre hay posibilidades de utilizar recursos que no están específicamente volcados a la atención de los turistas.

El modelo de sistema turístico de Leiper permite la localización de varios sectores del turismo, distinguiéndolos como pertenecientes mayoritariamente al origen, al destino o al espacio de tránsito. Por ejemplo, la mayor parte de los agentes de viaje se encuentran en la región generadora de turistas. La industria turística se hace presente en la región de destino. El sector de transporte está ampliamente representado por la región de la ruta de tránsito. Esa distinción espacial también puede ser encarada como una forma de categorización de los factores determinantes de los flujos turísticos (Oliveira, 2007). 
Neil Leiper, ya identifica el espacio geográfico que une a la demanda con la oferta turística, pero de igual manera no especifica claramente a un responsable de realizar las funciones de planeación, organización, dirección y control del sistema turístico, que asegure el flujo constante de las corrientes turísticas provenientes de la región de origen, no se puede apreciar su funcionar coordinado y armónico de sus partes, permitiendo la existencia de vacíos administrativos y de encadenamiento que debe de existir en el ciclo de funcionamiento normal en un sistema.

\section{Sistema turístico de la Organización Mundial de Turismo (OMT)}

La OMT no presenta un gráfico que explique el funcionamiento de su sistema turístico propuesto, sólo lo realiza por escrito, manifestando que el sistema turístico es un resultado complejo de interrelaciones entre diferentes factoresque hay que considerar conjuntamente desde una óptica sistemática, es decir, un conjunto de elementosinterrelacionados entre sí que evolucionan dinámicamente. Concretamente, se distinguen cuatro elementos básicos en el conceptode actividad turística:

La demanda: formada por el conjunto de consumidores o posibles consumidores de bienes y servicios turísticos.

La oferta: compuesta por el conjunto de productos, servicios y organizaciones involucrados activamente en la experiencia turística.

El espacio geográfico: base física donde tiene lugar la conjunción o encuentro entre la oferta y la demanda y en donde se sitúa la población residente, que si bien no es en sí misma un elemento turístico, se considera un importante factor de cohesión o disgregación, según se la haya tenido en cuenta o no a la hora de planificar la actividad turística.

Los operadores del mercado: son aquellas empresas y organismos cuya función principal es facilitar la interrelación entre la oferta y la demanda. Entran en esta consideración las agencias de viajes, las compañías de transporte regular y aquellos organismos públicos y privados que, mediante su labor profesional, son artífices de la ordenación y/o promoción del turismo (Sancho, 1998).

Esta propuesta de funcionamiento del sistema turístico, se la realiza con un enfoque sistémico, intentando coordinar armoniosamente sus partes, pero aún no se identifica el ciclo mecánico que debe de seguir rutinariamente cada una de ellas, al ritmo de un responsable de planeación, organización, dirección y control del sistema turístico, que asegure el desarrollo y efectividad de su funcionar. Además se observa una débil aplicación de la teoría de clúster o cúmulos que plantea Michael E. Porter en su libro, que explica que "Los cúmulos (clusters, en inglés) son concentraciones geográficas de empresas interconectadas, suministradores especializados, proveedores de servicios empresas e instituciones afines e industrias conexas 
que compiten pero que también cooperan” (Porter, 2003, pág. 203), parte fundamental de la competitividad e innovación que debe de existir en los servidores y/o empresarios del motor de la oferta turística, que les permita crear productos y servicios competitivos acorde a las exigencias y tendencias de las corrientes turísticas del mundo.

\section{Resultados y Discusión}

En la actualidad, la palabra turismo es muy común escucharla en cualquier lugar, en la radio, internet o televisión, e incluso en la calle, por personas de todas las áreas del conocimiento, lo trasmiten con tal fluidez que se evidencia fuertes discusiones al respecto, hasta llegar a una pregunta ¿Por qué no se ha desarrollado el turismo?, y ellos mismos suponen varias respuestas que giran en torno a la corrupción o inactividad de autoridades, en lo que al autor respecta, el turismo no se desarrolla cuando no se comprende el dinamismo coordinado y rutinario de las pates, elementos e integrantes que lo conforman, o aún no han armado el sistema con todas sus partes y comprendido su funcionamiento, teniendo presente que el tamaño de un sistema turístico es relativo al objetivo de análisis, en otras palabras no existe tamaño determinado para establecer el mismo, puede ser desde un destino turístico x, hasta de la biosfera.

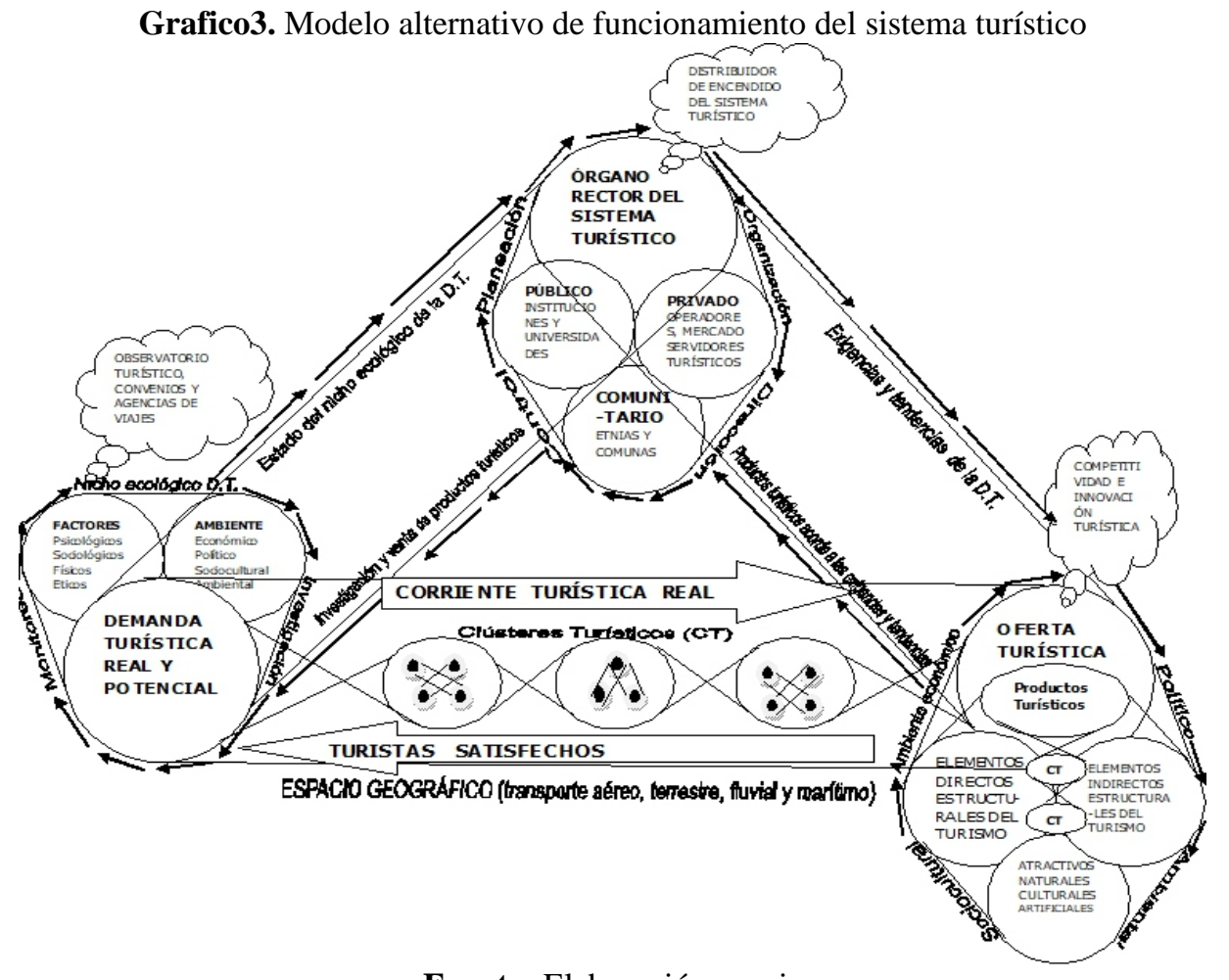

Fuente: Elaboración propia 
El presente modelo alternativo de funcionamiento del sistema turístico está basado fundamentalmente en los modelos propuestos por: Roberto Boullon, Neil Leiper y la OMT, consta de cuatro partes con sus respectivos elementos e integrantes interrelacionados entre sí, que se describen a continuación:

\section{1. Órgano Rector del Sistema Turístico}

El órgano rector, debe funcionar como el distribuidor de encendido del sistema turístico, que al transmitir fluidamente a los elementos y componentes de la oferta, el comportamiento, exigencias y tendencias de la demanda real y potencial, resultado de una constante investigación y monitoreo, permita la retroalimentación de productos turísticos acorde a las exigencias y tendencias de la demanda, a su vez el órgano rector, a través de las herramientas del marketing, debe incidir en el nicho ecológico de la demanda potencial a la hora que ellos tomen la decisión de viajar hacia un destino turístico, y compren los productos y/o servicios ofertados por su sistema, y así el funcionamiento del órgano rector debe ser mecánico, coordinado, armónico y rutinario, por lo que, para que su funcionar sea eficiente, tiene que estar integrado por los representantes elegidos democráticamente de los sectores: público, privado y comunitario del sistema turístico.

Público: está integrado por los representantes elegidos democráticamente de las unidades y/o departamentos de turismo de las organizaciones públicas del sistema en análisis, por ejemplo: si es de una provincia $\mathrm{x}$ de la República del Ecuador; serán los representantes del ministerio de turismo, prefectura, cantones y parroquias (urbanas y rurales) que se encuentren geográficamente en la provincia en análisis, además representantes académicos de las universidades que oferten la carrera de turismo, en esta provincia. Será un representante de cada unidad, departamento o universidad los que integren el órgano rector del sistema turístico.

Privado: está integrado por los representantes elegidos democráticamente de las cámaras u organizaciones de turismo legalmente constituidas, en la que, deben constar todos los servidores y/o empresarios de la oferta y espacio geográfico del sistema turístico, incluidos los operadores del mercado, sean agencias de viajes mayoristas o minoristas, teniendo presente que estos representantes serán los responsables directos de transmitir a sus representados la información acerca de la demanda turística real y potencial que les permita la creación o adaptación de los servicios y/o productos turísticos acorde a las exigencias y tendencias de la demanda turística. Será un representante de cada cámara u organización los que integren el órgano rector del sistema turístico. 
Comunitario: está integrado por los representantes elegidos democráticamente de las asociaciones u organizaciones de etnias y/o comunas que habiten geográficamente en el sistema turístico en análisis, de igual forma ellos serán los responsable de transmitir la información de la demanda, que les permita la creación y/o adaptación de sus servicios y/o productos turísticos acorde a las exigencias y tendencias de la demanda. Será un representante de cada asociación u organización los que integren el órgano rector del sistema turístico.

Esta primera parte del sistema turístico propuesto, tiene la función principal de investigar y monitorear periódicamente el nicho ecológico de la demanda turística real y potencial, transmitir habitualmente la información obtenida e incidir a la hora de la toma de decisión de viaje de la demanda turística potencial. Para ello el órgano rector tiene que cumplir las funciones de: planeación, organización, dirección y control del sistema turístico, haciendo uso de las herramientas de la administración (planes estratégicos de desarrollo, de seguimiento y control, operativos anuales, gerenciales, de manejo, entre otros) y del marketing.

Se han unido estos cuatro actores y sectores en el órgano rector del sistema turístico, con la finalidad de lograr una eficiente fluidez de información entre la demanda real-potencial y la oferta, mediante la creación y funcionamiento de un observatorio u organización de análisis del nicho ecológico de la demanda turística, que permita la creación de empresas turísticas desde la demanda, con sólido conocimiento de sus exigencias y tendencias, que evite el continuismo de crear microempresas desde la oferta sin conocimiento del comportamiento de la demanda, que ha llevado al cierre de muchas microempresas turísticas, a un deficiente servicio y/o funcionamiento del sistema turístico. La fluidez constante de información tiene que darse en todas las partes, elementos e integrantes del sistema turístico, iniciando en la investigación y monitoreo del nicho ecológico de la demanda turística (factores psicológicos, sociológicos, físicos, éticos y ambiente económico, político, sociocultural y ambiental) por parte del órgano rector del sistema turístico, si se dejara de transmitir la información desde y hacia la oferta a través de los sectores y actores público, privado, comunitario, estaría propenso a fallar hasta dejar de funcionar.

\section{Demanda Real y Potencial del Sistema Turístico}

Las corrientes turísticas real y potencial conforman la demanda del sistema turístico, que al momento de tomar la decisión de viajar, dependen de su nicho ecológico, distribuido en dos componentes; factores (económico, psicológico, sociológico, físico, ético) y ambientes(económico, político, sociocultural y ambiental). Entendiendo que la corriente turística real representa a los turistas que constan en las estadísticas del sistema en 
análisis, y la corriente turística potencial, son todos los residentes que mediante investigación de mercado, probablemente viajarán al sistema turístico en análisis.

El nicho ecológico de la demanda del sistema turístico, es el ambiente y actividades rutinarias que normalmente realizan en su lugar de residencia (trabajo, amigos, familia, tecnología). El estudio constante de su nicho ecológico, otorgará al órgano rector del sistema turístico, conocimiento suficiente que le permita incidir a través de las herramientas del marketing, en sus factores determinantes al momento de la toma de decisión de viajar hacia un destino turístico. Teniendo presente que la decisión de hacer turismo, es tomada en consenso con sus familiares, amigos y conocidos, previa investigación en internet, revistas, libros, agencias de viajes y comunidades virtuales, sobre los aspectos económico, político, cultural, ambiental y tecnológico del lugar elegido para viajar. Es decir tanto los factores: económico, psicológico, sociológico, físico y ético, como los ambientes: económico, político, sociocultural, ambiental y tecnológico del lugar elegido para viajar conforman el nicho ecológico de la demanda turística. Los dos componentes tienen la misma importancia en el turista a la hora de tomar la decisión de viajar hacia un destino turístico.

La demanda debe verse como el combustible que activa la gran industria turística del sistema, de los clúster y/o empresarios turísticos directos e indirectos del espacio geográfico y oferta, encargados de satisfacer a plenitud las necesidades de transporte, alojamiento, alimentación, recreación y salud de la corriente turística real, reactivando las economías del sistema a través de la redistribución del gasto turístico, al igual que la lluvia riega los sembríos de un agricultor. Como buen administrador el órgano rector del sistema turístico, debe asegurar el flujo constante de la corriente turística real, a través de la investigación y monitoreo de la misma, in situ y en especial, en su lugar de residencia, asegurando y descubriendo yacimientos de combustible (corrientes turísticas potenciales) para el motor de oferta turística.

\section{Espacio Geográfico del Sistema Turístico}

El espacio geográfico, está conformado por el transporte aéreo, terrestre, fluvial, marítimo, y los clúster turísticos ahí existentes, comprendiendo al transporte antes mencionado como organizaciones legalmente constituidas que operen en esta zona, transportando la demanda turística real, hacia la oferta y sus clúster turísticos como asociaciones de servidores o empresarios turísticos que se unen y ejecutan estrategias conjuntas, para ofertar servicios y productos turísticos de calidad. El espacio geográfico debe ser parte del itinerario de actividades de los paquetes, circuitos, programas y/oproductos turísticos que oferte el sistema. 
Cabe resaltar la importancia del transporte para el desarrollo del turismo, por lo que, la calidad de los servicios y productos turísticos que se ofrezcan en esta zona de transición entre la demanda y la oferta, debe de ser controlada bajo los mismos parámetros de rigurosidad y calidad que los servidores y/o empresarios de la oferta, por el órgano rector del sistema turístico.

\section{Oferta del Sistema Turístico}

Son todos los servicios y/o productos turísticos (atractivos+facilidades+accesibilidad) que a través de la innovación, tecnología, competitividad, talento humano, política y economía, se puedan crear y posicionar en el mercado. Estos productos turísticos están integrados por los atractivos naturales, culturales, artificiales y los elementos directos e indirectos del sistema turístico.

Atractivos naturales, culturales y artificiales:

Son el atractivo y motivo de viaje de los turistas; los atractivos naturales están compuestos por toda la belleza comparativa de biodiversidad y geografía de las ecozonas, ecoregiones, biomas o ecosistemas existentes en el sistema turístico en análisis. Los atractivos culturales se conforman de la diversidad de etnias y comunas existentes en la zona. Los atractivos artificiales son los fabricados por el hombre, existentes en el sistema turístico.

Todos los atractivos naturales, culturales y artificiales deben ser inventariados y jerarquizados de manera objetiva y profesional por el órgano rector del sistema turístico, sean estos; públicos, privados y/o comunitarios. Además esta información debe fluir con toda normalidad, tipo base de datos, con acceso de todos los servidores turísticos, teniendo presente que los atractivos antes mencionados son la plataforma para la creación de posibles productos turísticos.

Elementos estructurales directos:

Son todos los servidores y/o empresarios que legalmente constituidos integran el catastro turístico del sistema en análisis, giran en torno a la satisfacción de las necesidades de transporte, hospedaje, alimentación, recreación y bienestar de la corriente turística real, aquí podemos encontrar a establecimientos hoteleros, extrahoteleros, restaurantes, empresas de transporte aéreo-terrestre-fluvial o marítimo, establecimientos de recreación, parques temáticos, naturales, bares, supermercados, complejos deportivos entre otros que se encuentren operando en el sistema turístico.

El órgano rector del sistema turístico, debe proporcionar a todos los servidores y/o empresarios, información periódica del comportamiento (exigencias y tendencias) de la demanda turística real y potencial, por medio de los representantes públicos, privados, y comunitarios que lo integran, 
teniendo presente que, esta información debe guiar las funciones de planeación, organización, dirección y control del sistema turístico.

Todos los servidores y/o empresarios turísticos tienen que ser capacitados regularmente, por el órgano rector del sistema turístico propuesto, en temas de atención al cliente, manejo de grupos, innovación turística, relaciones públicas, funciones de la administración de una empresa, manejo de las herramientas del marketing, creación de productos turísticos competitivos, entre otros temas pertinentes a las exigencias y tendencias de las corrientes turísticas reales y potenciales de su sistema.

Los servidores y/o empresarios turísticos deben conformar clústeres que compartan y persigan objetivos y estrategias similares, como se puede apreciar en el gráfico del modelo de funcionamiento del sistema turístico propuesto, conjuntos de puntos conectados por líneas, eso significa que cada punto es un servidor y/o empresario turístico, cada conjunto de puntos es un clúster turístico y las líneas que los unen representan la fluidez de información que tiene que existir entre empresarios y/o clústeres turísticos, esta información debe girar en torno a la experiencia de atención a los turistas de parte de cada uno de ellos, sin guardarse ninguna experiencia con síntomas de celos empresariales, no pueden verse entre ellos como competencia, porque la competencia está en otros sistemas turísticos, más no en este sistema en análisis, mientras más gruesa sea la línea que una a los servidores y/o clúster turísticos mayor será la efectividad y/o rentabilidad del sistema y mientras más delgada sea la línea antes mencionada, menor será la efectividad con la que funcione el sistema turístico, que con el tiempo dejará de funcionar y existirán malas experiencias en los turistas, bajo aprovechamiento sostenible del gasto turístico, no reactivación de la economía, pobreza, cierre de empresas, entre otros.

La innovación tecnológica turística con base a la información del comportamiento de la demanda real-potencial y experiencias de atención a la corriente turística in situ, debe guiar la creación de nuevos productos turísticos, que generen un constante dinamismo (actividades-servicios adaptados a las exigencias y tendencias de la demanda) en los servidores y/o empresarios de la oferta turística, que no permita llegar al declive del sistema en análisis. Además, se debe crear un software que permita la fluidez de la información ates mencionada entre todos los servidores y/o empresarios turísticos, con oficinas en los terminales terrestres, aeropuertos y puertos marítimos, que satisfaga las necesidades de alojamiento, alimentación, recreación entre otros, de los turistas que no hayan adquirido un inclusive tour (todo incluido). El software debe contar con un amplio portafolio de servicios, basado en costos, que permitan al turista escoger opciones y automáticamente obtenga el servicio que satisfaga a plenitud sus necesidades, con tan solo pinchar en una opción del software. 
Elementos Indirectos del Turismo:

Son las instituciones públicas encargadas de la construcción de vías de comunicación y trasporte, servicios generales como: agua potable, luz, alcantarillado, salud, educación eindustrias conexas, sean estas mixtas, privadas y/o comunitarias que ofrezcan servicios bancarios, tecnológicos, de seguros entre otros, que no necesariamente tengan contacto en primera instancia con el turista, pero que son de suma importancia para el diseño de productos y funcionamiento efectivo del sistema turístico.

Necesariamente en la formación de clústeres y productos turísticos de la oferta, deben constar los elementos indirectos del turismo, de acuerdo a la pertinencia de sus objetivos. Además la oferta turística debe vestirse de un buen ambiente político, económico, y sociocultural, que se vea reflejado en los ambientes que conforman el nicho ecológico de la demanda turística, puestos en valor por los residentes a la hora de tomar la decisión de viajar hacia un destino turístico.

\section{Funcionamiento del Sistema Turístico Propuesto}

La importancia y jerarquía de las partes, es relativo a los objetivos de análisis de los investigadores, pero de cierta forma se concatenará el engranaje de la mecánica de las partes del sistema turístico propuesto, de la siguiente forma.

El órgano rector del sistema turístico con todos sus integrantes, investiga y monitorea el nicho ecológico de la demanda turística real y potencial, transmitiendo fluidamente sus resultados a los servidores y/o empresarios turísticos, asegurando la corriente turística real, vendiendo los productos diseñados acorde a sus exigencias y tendencias, através de operadores del mercado, oficinas propias, convenios interinstitucionales, políticas entre otros y al mismo tiempo incide por intermedio de las herramientas del marketing, en la toma de decisión de viaje de la corriente turística potencial en su lugar de residencia, asegurando yacimientos de combustible para los servidores del motor de la oferta turística y espacio geográfico, que al recibir la información constante del comportamiento de la demanda turística real y potencial, se adaptan, capacitan y mejoran sus empresas acorde a las sugerencias de la demanda, para satisfacer a plenitud sus necesidades, para ello han conformado clústeres turísticos de acuerdo a sus objetivos de funcionamiento, incluso se han conectado con líneas gruesas, con otros clústeres turísticos de la oferta y del espacio geográfico del sistema, generando mediante la innovación, competitividad y tecnología, productos turísticos acorde a las necesidades de la demanda real y potencial, que inmediatamente son puestos en oferta en sus lugares de residencia,por el órgano rector de del sistema turístico, y así sucesivamente tiene su ciclo mecánico de funcionamiento normal este sistema propuesto, que al sentir 
alguna falla técnica o de comportamiento en cualquiera de los integrantes, elementos o partes, comenzará a minorar su ritmo de efectividad y productividad, hasta dejar de funcionar. El éxito del desarrollo del turismo en una sociedad, radica en la comprensión del funcionamiento coordinado, armónico, constante y rutinario de cada una de las partes que conforman el sistema turístico, como un cuerpo mecánico completo, entendiendo que su efectividad depende del buen estado de cada uno de sus componentes, no puede verse el turismo como una actividad de componentes aislados, por mas intangible que se vea, su estructura es real y su funcionar es mecánico.

\section{Conclusion}

De la misma forma que para un médico es el cuerpo humano, que para un mecánico automotriz es el motor a combustión, es para un profesional en turismo el sistema propuesto, quien debe ser conocedor-experto del funcionamiento de las partes, elementos e integrantes que lo conforman, para que pueda determinar mediante análisis, los factores que no están permitiendo que se desarrolle efectivamente el turismo en una sociedad; el mejor profesional en turismo deberá ser, el que acorde a la problemática analizada, proporcione estrategias, planes de desarrollo, planes de sitio, recetas más efectivas que permitan el mayor desarrollo, uso sostenible o efectividad en los sistemas turísticos del mundo.

La mecánica del turismo es evidente en cada rutina coordinada de las partes, elementos e integrantes que conforman el sistema turístico, resaltando que si un elemento e integrante de cualquiera de las cuatro partes, se encuentra en mal estado o no cumple con las condiciones descritas anteriormente, el turismo no se desarrollará efectivamente, produciendo un estancamiento incomprensible para las diferentes áreas del conocimiento e intentos fallidos de estrategias de desarrollo y gastos equívocos de recursos humanos y económicos.

El sistema turístico está compuesto de la suma, esfuerzo y apoyo de todos los actores (públicos, privados y comunitarios) del desarrollo de una sociedad, la complejidad de esta industria radica, en la armonía con que deben sincronizar el actuar y proceder en la construcción, ejecución y control de las estrategias de desarrollo turístico planificadas por sus representantes en el órgano rector del sistema propuesto.

\section{References:}

1. Boullón, R. C. (2006). Planificación del Espacio Turístico. México: Trillas.

2. Carabias, J., \& Meave, V. C.-S. (2009). Ecología y Medio Ambiente en el siglo XXI. Mexico: Pearson Edicación. 
3. Masaro, R. M. (2008). Modelos de Competitividad para Destinos Turísticos en el Marco de la Sostenibilidad. Revista de Administración Contemporánea , 799.

4. Oliveira, S. G. (2007). Modelos Teóricos aplicados al Turismo. Estudios y Perpectivas en Turismo.

5. Orozco, D. (09 de Noviembre de 2014). Ciencia M. Recuperado el 25 de Abril de 2015, de http://conceptodefinicion.de/mecanica/

6. Porter, M. E. (2003). Ser Competitivo Nuevas aportaciones y conclusiones. Barcelona-España: Deusto.

7. Sancho, A. (1998). Introducción al Turismo. Organización Mundial de Turismo. 